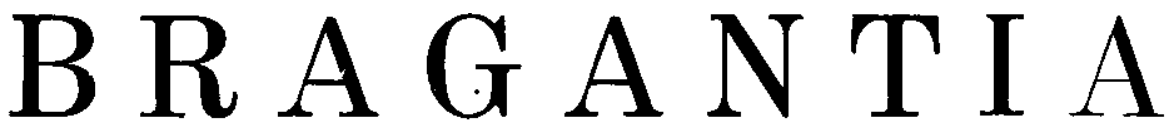

Boletim Técnico do Instituto Agronômico do Estado de São Paulo

Vol. 17

Campinas, dezembro de 1958

N.o 17

\title{
BASES DO SOLO E SEU COMPORTAMENTO \\ FRENTE A EXTRATORES ÁCIDOS (*)
}

\author{
F. DA Costa Verdade
}

Engenheiro-agrônomo, Seção de Agrogeologia, Instituto Agronômico

\section{RESUMO}

Já foi verificado anteriormente que certos solos do Estado de São Poulo apresentom os elementos Co, $\mathrm{Mg}$ e $\mathrm{K}$ em formas "fixas", isto é, não trocáveis. Procurou-se neste trabalho estudar o comportamento dessas bases, frente a diversas concentraçōes do extrator $\mathrm{HNO}_{3}$, desde $0,005 \mathrm{~N}$ até $2,000 \mathrm{~N}$, comparando os resultados com os obtidos para diversos volumes do extrator acetato de amônio $1 \mathrm{~N}, \mathrm{pH} 7$.

Os dodos experimentais indicam que o extrator ácido retira as mesmos quantidades dos elementos $\mathrm{Ca}, \mathrm{Mg}$ e $\mathrm{K}$ que o acetato de amônio e as variações encontrados para as diversas concentraçōes de $\mathrm{HNO}_{3}$ são os mesmas encontradas para volumes diferentes do ocetato de amônio. Confirma-se portanto, que nos extratores ácidos são determinados os elementos trocáveis do solo.

As formas "fixos" dos citados elementos sõo bastante resistentes à sua remoção, não sendo atocadas por ácidos à concentração $2 \mathrm{~N}$. Sendo a nutrição mineral das plantas, relativamente ao $\mathrm{Co}, \mathrm{Mg}$ e $\mathrm{K}$, baseada no troca com o complexo ou com a solução do solo, e não se aceitando que os vegetais possam criar condiçōes mcis enérgicas que o $\mathrm{HNO}_{2} 2 \mathrm{~N}$ para solubilização das formas "fixas", conclui-se que essa nutrição só se processe através das bases trocáveis do solo.

Por fim, estudam-se as variaçōes dos teores em bases obtidas pelos extratores ácidos para solos de diversas formações geológicas e compara-se com os teores determinados pelo acetato de amônio.

\section{1 - INTRODUÇÃO}

Os solos zonais do Estado de São Paulo, devido às condições climáticas e de vegetação, são predominantemente latossolos, amarelo-vermelho podzólicos, ou as transições entre ambos. Esta don-inância dos Grandes Grupos de Solos indica a ausência de sais no perfil e a insaturação do complexo por bases. Os métodos de extração das bases trocáveis são os mais simples e faltam, portanto, as complicações que surgem quando existem os sais solúveis em água e os carbonatos.

(*) Trabalho apresentado no V1 Congresso de Ciência do Solo, realizado na Bahia, em Julho de 1957.

Recebido para publicaçāo em 29 de janeiro de 1958. 
Em virtude das condições dos elementos trocáveis no solo e da facilidade nas operações químicas, a Seção de Agrogeologia vem utilizando $\circ \mathrm{HNO}_{3} 0,05 \mathrm{~N}$ como extrator de bases. Emprega-se, também, a percolação em lugar da agitação, que é mais comumente utilizada. O emprêgo de soluções ácidas para tal extração é bastante antigo tendo sido, ao que parece, proposto inicialmente por Gedroiz, citado por Piper (8).

O extrator acetato de amônio, $\mathrm{pH}=7,00$, em solução $1 \mathrm{~N}$ é considerado como o melhor processo para a determinação dos trocáveis e considerações a respeito são citadas por Piper e Schollenberger $(\mathbf{8}, \mathbf{9})$.

A solução de ácido nítrico $0,05 \mathrm{~N}$ foi comparada com o extrator acetato de amônio, dando resultados equivalentes, como indicaram recentemente Catani e Küpper $(1,3)$. Esses autores ainda verificaram que o cálcio do solo estava quase todo na forma trocável e o $\mathrm{K}+$ e $\mathrm{Mg}^{++}$apresentavam-se, além da permutável, em formas "fixas", não trocáveis.

À vista dêsses resultados procurou-se estudar o comportamento dás bases do solo frente a diferentes concentrações do extrator $\mathrm{HNO}_{3}$ e se as formas consideradas como "fixas" estão fortemente retidas e, portanto, inaproveitáveis para as plantas. Consideram-se no presente trabalho apenas as bases $\mathrm{K}^{+}, \mathrm{Ca}^{++}$e $\mathrm{Mg}^{++}$, rejeitando-se $\circ \mathrm{Mn}^{++}$ pela dificuldade em separar o trocável do não trocável (2), $\circ \mathrm{NH}^{+}{ }_{4}$ pelo seu dinamismo e o $\mathrm{Na}^{+}$pela pequena importância em nossos solos e na nutrição vegetal.

\section{2 - MATERIAIS E MÉTODOS}

Os solos considerados no presente trabalho provêm das formaçōes geológicas mais extensas e de maior importância para a agricultura do Estado. A seleção de solos segundo o material original resultou de ser o teor mineral trocável ou "fixo", intimamente ligado à rocha-mater, pelo menos nas condições de São Paulo.

$\mathrm{Na}$ extração dos trocáveis foi empregado um volume da concentração que fornecesse excesso de $\mathrm{H}^{+}$e removesse efetivamente as bases (volumes pequenos, mesmo com concentração de $\mathrm{H}^{+}$suficiente, deixam, na percolação, de retirar as bases). 
As soluções tituladas de ácido nítrico que foram empregadas para a percolação de $20 \mathrm{~g}$ de solo, segundo técnica indicada por Paiva e outros (7), foram: $2000 \mathrm{ml}$ em $0,005 \mathrm{~N} ; 2000 \mathrm{ml}$ em $0,010 \mathrm{~N}$; $400 \mathrm{ml}$ em $0,050 \mathrm{~N} ; 266,7 \mathrm{ml}$ em $0,075 \mathrm{~N} ; 200 \mathrm{ml}$ em $0,500 \mathrm{~N}$; $200 \mathrm{ml} \mathrm{em} 1,000 \mathrm{~N} ; 200 \mathrm{ml} \mathrm{em} \mathrm{2,000} \mathrm{N}$.

Admitindo-se variaçōes na quantidade de bases permutáveis quando volumes diversos de acetato de amônio são empregados, devidas provàvelmente aos êrros de amostragem e de manuseio na marcha analítica, foram utilizados neste estudo os volumes de 100,200,300 e $400 \mathrm{ml}$ dêsse extrator. A técnica empregada para preparo do reativo e percolação com o acetato pode ser encontrada em outro trabaTho (10).

Os estratos, depois da percolação, sofriam tratamentos especiais como seguem:

Soluçōes ácidas - As soluçōes são concentradas ao máximo possivel em frascos de Erlenmeyer de $250 \mathrm{ml}$, resfriadas e tratadas com solução oxidante $\left(3 \mathrm{ml}\right.$ de $\mathrm{HCl}$ concentrado para $3 \mathrm{ml}$ de $\mathrm{HNO}_{3}$ concentrado) no bico de gás, onde permanecem até quase a secura. Êste tratamento visa destruir a matéria orgânica e não sendo suficiente para tal fim, repete-se o tratamento de oxidação. O resíduo é diluido com um pouco de água destilada e, no caso do aparecimento de precipitado galatinoso de sílica, filtrado para balōes volumétricos donde se retiram as alíquotas para dosagem dos elementos que interessam.

Soluções de acetato de amônio - O extrato, em frascos de Erienmeyer de $250 \mathrm{ml}$, é concentrado ao máximo e a seguir, em bico de gás, destrói-se a matéria orgânica com solução oxidante $(5 \mathrm{ml}$ de $\mathrm{HNO}_{3}$ e $5 \mathrm{ml}$ de $\mathrm{HCl}$, ambos concentrados). Não havendo desprendimento de vapores avermelhados, os ácidos estão sendo consumidos para o desprendimento de ácido acético e deve-se repetir o tratamento inicial até a destruição das substâncias orgânicas. $O$ volume é concentrado no bico de gás e depois transferido para cápsula e sêco em banho-maria. A cápsula é aquecida preliminarmente em banho elétrico e depois em forno-mufla onde permanece durante meia hora, à temperatura máxima de $400^{\circ} \mathrm{C}$. Uma vez resfriada a cápsula, trata-se o resíduo calcinado com $3 \mathrm{ml}$ de $\mathrm{HCl}(1+1)$ e leva-se para o banhomaria, onde deverá permanecer pelo menos meia hora depois de sêco. Retoma-se o resíduo com $5 \mathrm{ml}$ de $\mathrm{HNO}_{3}(1+9)$ e a solução resul- 
tante é filtrada para balóes volumétricos, donde se retiram alíquotas para as diversas determinações.

Marcha analítica para determinação do $\mathbf{K}^{+}, \mathbf{C a}^{++}$e $\mathbf{M g}^{++}-$ A dosagem do $\mathrm{Ca}$ seguiu as indicações de Paiva e outros $(\mathbf{7})$; do $\mathrm{K}$, a marcha assinalada por Catani e Paiva (4); e do $\mathrm{Mg}$, a apresentada por Küpper (6).

Como as soluções de $\mathrm{HNO}_{3}$ concentradas dissolvem muito ferro e olumínio, êstes podiam operar a co-precipitação dos íons a serem dosados, como indicam Kolthoff e Sandell (8). A dupla precipitação daqueles hidróxidos em soluções de diversos solos indicou que só nas "terras roxas" existia uma diminuição ponderável por co-precipitação do $\mathrm{Ca}^{++}$e $\mathrm{Mg}^{+}+$. Por outro lado, o teor de potássio era sempre bem menor nas amostras que sofriam a dupla precipitação. Para as terras roxas, consequientemente, os resultados de $\mathrm{Ca}^{++}$e $\mathrm{Mg}^{++}$foram os obtidos por dupla precipitação, e de $\mathrm{K}+$ por uma precipitação simples, apesar de as alterações no resultado dos primeiros dois elementos não serem de magnitude a impedir as conclusões visadas neste estudo. Nāo houve repetiçóes para uma mesma concentração de extrator, exceto quando os resultados eram discordantes entre as soluções de títulos aproximados. Neste caso eram feitas no mínimo duas repetições.

\section{3 - RESULTADOS EXPERIMENTAIS}

O estudo do comportamento das bases permutáveis do solo frente a diversas concentrações do extrator ácido nítrico e os resultados com diversos volumes do acetado de amônio, como extrator, permitiram confirmar alguns fenômenos da troca de bases e a eficiência dos extratores ácidos.

\section{1 - RELAÇĀO ENTRE OS DIVERSOS TIPOS DE EXTRAÇÃO DE BASES}

Os resultados comparativos entre as diversos extrações de bases nos solos do Estado, podem ser vistos nas figuras 1, 2 e 3.

Para se relacionarem os teores removidos pelas soluções de $\mathrm{HNO}_{3}$ em diversas concentrações com os encontrados na percolação do solo com $200 \mathrm{ml}$ de ccetato de amônio $1 \mathrm{~N}, \mathrm{pH} \mathrm{7,} \mathrm{tomada} \mathrm{como} \mathrm{base,}$ procurou-se o valor relativo dessas determinações o que se obteve mul- 


\section{VERDADE}

tiplicando o teor de dada extração por 100 e dividindo o produto pelo teor achado nesse volume de acetato de amônio. Nestas condições, as figuras 1,2 e 3 apresentam a porcentagem de variação duma extração em função do teor encontrado no acetato, considerado como básico. Operando-se da mesma maneira com os teores achados nos percolodos de 100,300 e $400 \mathrm{ml}$ de acetato de amônio obtêm-se as variações dos elementos quando se empregam volumes diferentes de acetato.

A figura $\mathrm{l}$ indica que o $\mathrm{Ca}^{++}$é retirado do solo nas mesmas quantidades desde as soluções $0,005 \mathrm{~N}$ até $2,000 \mathrm{~N}$ em $\mathrm{HNO}_{3}$, e as variações aí encontradas são da mesma magnitude que as variações nos diferentes volumes de acetato. A figura mostra uma tendência para as soluções concentradas darem maiores teores que as diluidas, porém sem reflexo nas considerações já expendidas.

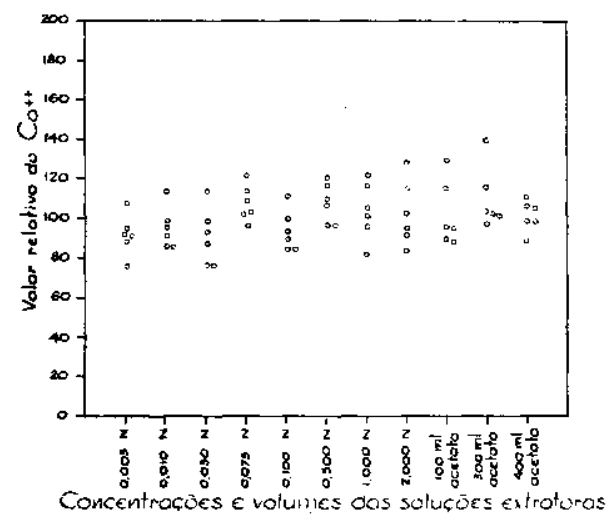

Figura 1. - Valor relativo do $\mathrm{Ca}++$, paro os diversos tipos de extratores.

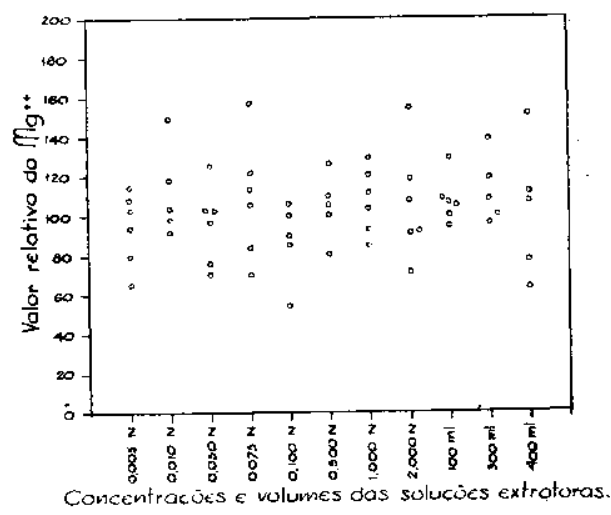

Figura 2. - Volor relativo do $\mathrm{Mg}++$, para os diferentes tipos de extrotores.

A figura 2, onde se estuda $\circ \mathrm{Mg}^{++}$, e a figura $3, \circ \mathrm{K}^{+}$, apresentam as mesmas relaçōes estabelecidas para o $\mathrm{Ca}^{++} \mathrm{e}$, portanto, com as mesmas conclusōes ai apresentadas. Ambas as figuras apresentam maior amplitude de variação do índice para o mesmo extrator que na figura $\mathrm{l}$, sendo a do $\mathrm{K}+$ maior que a do $\mathrm{Mg}^{++}$.

Uma observação a ser feita pelos resultados expostos nas figuras 1, 2 e 3, é que existe uma grande variação nas dosagens dos elementos trocáveis. Ela não pode ser explicada pelos erros inerentes co método ou ao manuseio rotineiro do percolado, porque em con- 
dições normais de laboratório tal variação não se verifica nas repetições. Evidentemente, neste estudo houve muito trabalho com as soluções, pela concentração do líquido, tratamento com oxidantes etc., o que aumentava o êrro analítico, porém, outro deve ser o motivo. Os teores trocáveis nos solos de São Paulo são baixos e pelo menos a metade dos solos usados pertence à categoria de solos com teores muito baixos, quando pequenas alterações nas dosagens produzem grande porcentagem de êrro. É frisante que as variações seguem a ordem de quantidade dos elementos no solo, isto é, a base em maior porcentagem, $\mathrm{Ca}$, apresenta menor êrro e vice-versa para o $\mathrm{K}^{+}$.

Pelos dados apresentados, é de se concluir que a capacidade de troca de bases nestes solos é uma propriedade bastante característica, mantendo-se e resistindo a variações amplas de concentração do extrator ácido. Nas condições da experiência ela se manteve desde a concentração 0,005 até $2,000 \mathrm{~N}$ em ácido nítrico, e não houve indicações de retirada das formas "fixas" (2). O teor das bases trocáveis é, portanto, independente da concentração

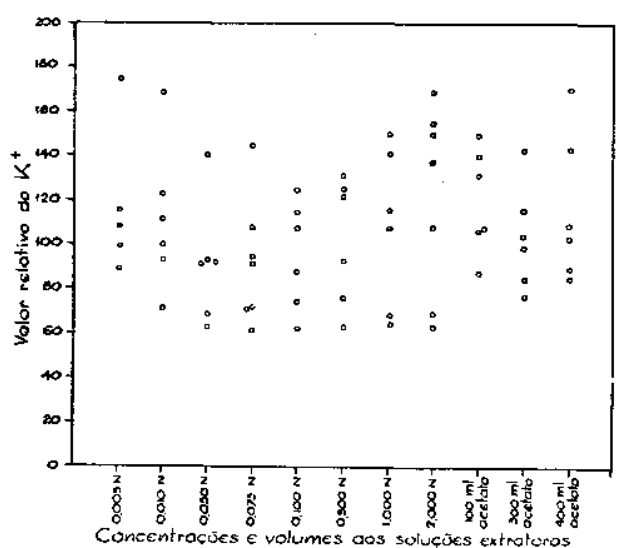

Figura 3. - Valor relativo do $\mathrm{K}+$, para os diferentes tipos de extratores. do extrator e, levando-se em consideração o acetato de amônio, independe do tipo de extrator (dentro de certos limites). Estas propriedades já são bem conhecidas $(1,3)$. Para o caso do $\mathrm{HNO}_{3}$ pode-se concluir que a extração das bases, dentro dos limites estudados, relaciona-se com o número de íons hidrogênio que passam pelo solo e não da sua concentração.

Nos laboratórios da Seção é usada como extrator de bases a solução titulada de $\mathrm{HNO}_{3} 0,05 \mathrm{~N}$, e o presente trabalho mostra que se pode trabalhar perfeitamente com soluções $\pm 0,05 \mathrm{~N}$. Esta parece ser a melhor concentração porque fornece iônios suficientes para a troca das bases (trabalha-se com $100 \mathrm{ml}$ para $10 \mathrm{~g}$ de solo) e por outro lado extrai pouco $\mathrm{Fe}^{+++}, \mathrm{Al}+++$ e matéria orgônica.

E interessante também notar que as formas "fixas" determinadas 


\section{Verdade}

por Catani e Küpper (3) são bastante resistentes à extração, visto que o $\mathrm{HNO}_{3} 2 \mathrm{~N}$ só retira as bases trocáveis.

Como as plantas absorvem as bases pela troca de elementos com as partículas ou com a solução do solo, uma conclusão interessante sôbre a nutrição mineral pode ser obtida dos resultados apresentados. Não podemos admitir que as plantas estabeleçam condições mais enérgicas para ataque ao solo que uma solução $2 \mathrm{~N}$ em $\mathrm{HNO}_{3}$. Como esta solução, em solos do Estado, só extrai as bases trocáveis, não retirando nada das formas "fixas" ou do "potencial" do solo, é lícito concluir que os vegetais só contam para a sua nutrição com as bases trocóveis.

\section{2 - EXTRAÇÃo DE bASES PARA OS DIFERENTES SOLOS}

O comportamento dos solos de diferentes origens geológicas, quando as bases são submetidas à extração com $\mathrm{HNO}_{3}$ a diversas concentrações e a diferentes volumes de acetato de amônio $1 \mathrm{~N}$, pode ser estudado pelo quadro 1 e figuras 1,2 e 3.

O estudo das bases nos três solos principais, Terra-Roxa (diabase), Massapê-Salmourão (gnaiss e granito) e o Bauru (arenito Bauru), indicou que o primeiro apresenta a maior variação em teores de elementos nas diversas soluções ácidas. Verifica-se, também, que os maiores variações, tanto quanto à acidez como ao acetato de amônio, resultam nos solos com altos teores em bases. Dos três solos só se apresentam os gráficos para os solos de diabase, que têm as maiores oscilações no teor de $\mathrm{Ca}^{++}, \mathrm{Mg}^{++}$e $\mathrm{K}^{+}$.

Nas Terras-Roxas (figuras 4, 5 e 6), admitindo a

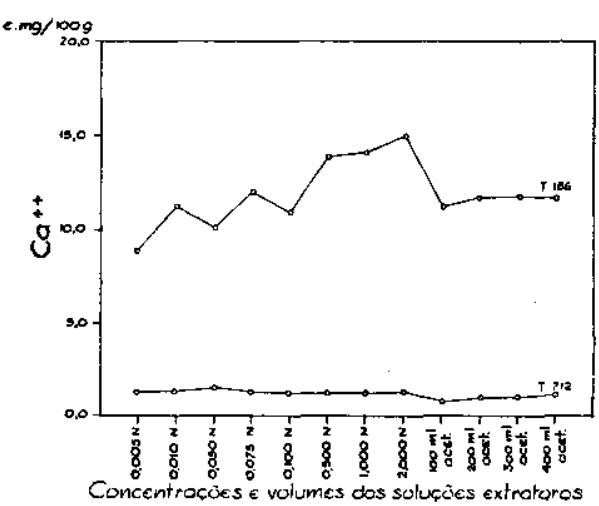

Figura 4. - Variação do teor de $\mathrm{Ca}++$ no Terra Roxa, segundo os diferentes extratores. generalização dos resultados obtidos, há maior constância do teor de $\mathrm{K}^{+}$frente à acidez do que em volumes crescentes de acetato. Considerando o extrator acetato 
como o mais exato para a determinação das bases trocáveis há equivalência com o extrator ácido. Para o $\mathrm{Mg}^{++}$e $\mathrm{Ca}^{++}$há constância de teores para o extrator acetato e menor para os extratores ácidos. Apesar das oscilações nos últimos, o autor julga ainda haver equivalência entre os resultados pelos dois processos.

QUADRo 1. - Variação do teor das bases trocáveis numa mesma amostra de solo, quando determinadas em extratos de diversas concentrações de ácido nítrico e percolados de diversos volumes de acetato de amônio $1 \mathrm{~N}, \mathrm{pH} 7$

\begin{tabular}{|c|c|c|c|c|c|}
\hline \multirow{2}{*}{$\begin{array}{l}\text { Formação } \\
\text { geologico }\end{array}$} & \multirow{2}{*}{$\begin{array}{l}\text { Material } \\
\text { original }\end{array}$} & \multirow{2}{*}{ Extrator } & \multicolumn{3}{|c|}{ Limites de varioção em $100 \mathrm{~g}$ de solo } \\
\hline & & & $\mathrm{Ca}++$ & $\mathrm{Mg}++$ & $\mathrm{K}+$ \\
\hline \multirow{4}{*}{ Arqueano } & & & $e . m g$ & $e . m g$ & $e . m g$ \\
\hline & Gnaiss & $\begin{array}{l}\mathrm{HNO}_{3} \\
\text { acetato }\end{array}$ & $\begin{array}{r}10,1-11,9 \\
9,9-10,9\end{array}$ & $\begin{array}{r}2,0-2,5 \\
2,1-2,8\end{array}$ & $\begin{array}{l}0,15-0,23 \\
0,23-0,25\end{array}$ \\
\hline & $\begin{array}{l}\text { Xisto com } \\
\text { restos de } \\
\text { feldspatos }\end{array}$ & $\begin{array}{l}\mathrm{HNO}_{2} \\
\text { acetato }\end{array}$ & $\begin{array}{l}19,7-20,9 \\
21,4-24-0\end{array}$ & $\begin{array}{r}0,5-1,0 \\
0,84-0,9\end{array}$ & $\begin{array}{l}0,13-0,18 \\
0,10-0,14\end{array}$ \\
\hline & Gnaiss & $\begin{array}{l}\mathrm{HNO} \\
\text { acetato }\end{array}$ & $\begin{array}{l}6,8-8,2 \\
7,2-8,0\end{array}$ & $\begin{array}{r}4,1-4,8 \\
3,5-3,7\end{array}$ & $\begin{array}{l}0,43-0,50 \\
0,36-0,40\end{array}$ \\
\hline Botucatu & Diabose & $\begin{array}{l}\mathrm{HNO}_{3} \\
\text { acetato }\end{array}$ & $\begin{array}{l}1,2-1,3 \\
0,9-1,0\end{array}$ & $\begin{array}{l}0,5-0,7 \\
0,2-0,5\end{array}$ & $\begin{array}{l}0,04-0,08 \\
0,05-0,07\end{array}$ \\
\hline Glacial & $\begin{array}{l}\text { Arenito } \\
\text { e } \\
\text { Diabase }\end{array}$ & $\begin{array}{l}\mathrm{HNO}_{\mathrm{s}} \\
\text { acetato }\end{array}$ & $\begin{array}{l}10,0-14,9 \\
11,3-11,8\end{array}$ & $\begin{array}{l}2,2-3,7 \\
2,4-2,6\end{array}$ & $\begin{array}{l}0,44-0,70 \\
0,49-0,84\end{array}$ \\
\hline \multirow[t]{2}{*}{ Bauru } & Arenito & $\begin{array}{l}\mathrm{HNO}_{s} \\
\text { acetoto }\end{array}$ & $\begin{array}{c}6,0-6,3 \\
6,10\end{array}$ & $\begin{array}{c}0,6-0,7 \\
0,80\end{array}$ & $\begin{array}{l}0,09-0,13 \\
0,08-0,15\end{array}$ \\
\hline & Arenito & $\begin{array}{l}\mathrm{HNO}_{3} \\
\text { acetato }\end{array}$ & $\begin{array}{l}0,9-1,1 \\
1,2-1,5\end{array}$ & $\begin{array}{l}0,4-0,6 \\
0,5-0,7\end{array}$ & $\begin{array}{l}0,09-0,13 \\
0,12-0,15\end{array}$ \\
\hline \multirow[t]{2}{*}{ Glaciol } & Tileito & $\begin{array}{l}\mathrm{HNO}_{3} \\
\text { acetato }\left(^{*}\right)\end{array}$ & $\begin{array}{c}11,9-14,1 \\
12,1\end{array}$ & $\begin{array}{c}2,0-2,5 \\
2,2\end{array}$ & $\begin{array}{c}0,45-0,70 \\
0,5\end{array}$ \\
\hline & Arenito & $\begin{array}{l}\mathrm{HNO}_{3} \\
\text { acetato }\end{array}$ & $\begin{array}{l}0,8-1,2 \\
0,9-1,1\end{array}$ & $\begin{array}{l}0,4-0,6 \\
0,3-0,5\end{array}$ & $\begin{array}{l}0,06-0,09 \\
0,06-0,08\end{array}$ \\
\hline Quaternário & $\begin{array}{l}\text { Resíduos } \\
\text { orgânicos }\end{array}$ & $\begin{array}{l}\mathrm{HNO}_{3} \\
\text { acetato (*) }\end{array}$ & $\begin{array}{c}0,8-1,3 \\
0,6\end{array}$ & $\begin{array}{c}0,6-1,2 \\
1,4\end{array}$ & $\begin{array}{l}0,40-0,60 \\
0,40-0,60\end{array}$ \\
\hline Botucatu & Arenito & $\begin{array}{l}\mathrm{HNO}_{3} \\
\text { acetato }\end{array}$ & $\begin{array}{l}0,9-1,2 \\
0,9-1,1\end{array}$ & $\begin{array}{l}0,3-0,8 \\
0,4-0,5\end{array}$ & $\begin{array}{l}0,06-0,08 \\
0,05-0,09\end{array}$ \\
\hline Terciário & Argilitos & $\begin{array}{l}\mathrm{HNO}_{3} \\
\text { acetoto }\end{array}$ & $\begin{array}{l}0,8-1,0 \\
0,8-1,3\end{array}$ & $\begin{array}{l}0,3-0,8 \\
0,4-0,5\end{array}$ & $\begin{array}{r}0,09-0,13 \\
0,08-0,13\end{array}$ \\
\hline Corumbataí & Argilitos & $\begin{array}{l}\mathrm{HNO}: \\
\text { acetato }\end{array}$ & $\begin{array}{l}0,2-0,5 \\
0,3-0,6\end{array}$ & $\begin{array}{l}0,2-0,4 \\
0,2-0,4\end{array}$ & $\begin{array}{c}0,04-0,08 \\
0,05\end{array}$ \\
\hline
\end{tabular}

$\left(^{*}\right)$ Dosagem em $200 \mathrm{ml}$ de acetato de amônio.

(**) Dosagens nos volumes de 200 a $400 \mathrm{ml}$ de acetato de amônio. 
Nos solos do Arqueano (gnaiss e granito) verificou-se inversão na ordem indicada para a Terra-Roxa. Os teores de $\mathrm{K}+$ são mais constantes para as soluções acetato e os teores de $\mathrm{Ca}^{++}$e $\mathrm{Mg}^{++}$são mais constantes para os extratores ácidos.

Nos solos originados do arenito de Bouru repetem-se os dados já indicados para as Terras-Roxas.

No quadro 1 encontram-se os dados referentes aos solos das formações geológicas mais importantes. Nesse quadro são apresentadas as variações nos teores de $\mathrm{Ca}^{++}$, $\mathrm{Mg}^{++}$e $\mathrm{K}+$ para os extratores ácidos e para os diversos volumes de acetato de amônio I $\mathrm{N}, \mathrm{pH} 7$.

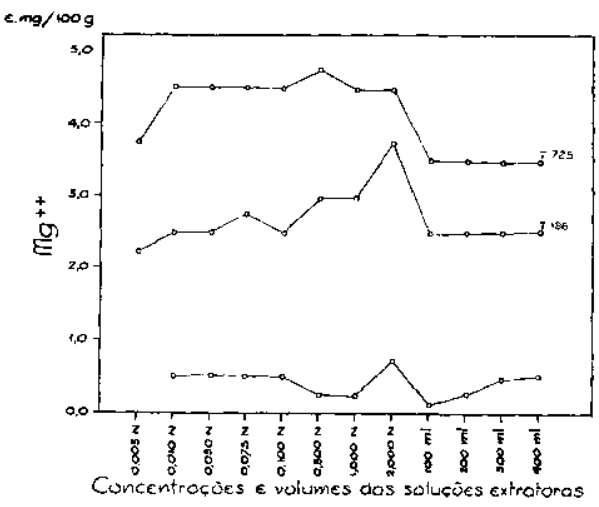

Figura 5. - Variação do teor de $\mathrm{Mg}++$ no Terro-Roxa, segundo os diferentes extratores.

\section{4 - CONCLUSÕES}

Pelos resultados obtidos no presente trabalho podem ser condensadas as seguintes conclusões.

a) Confirma-se que os extratores ácidos podem ser empregados em substituição ao método clássico do acetato de amônio para remoção das boses trocáveis, quando os

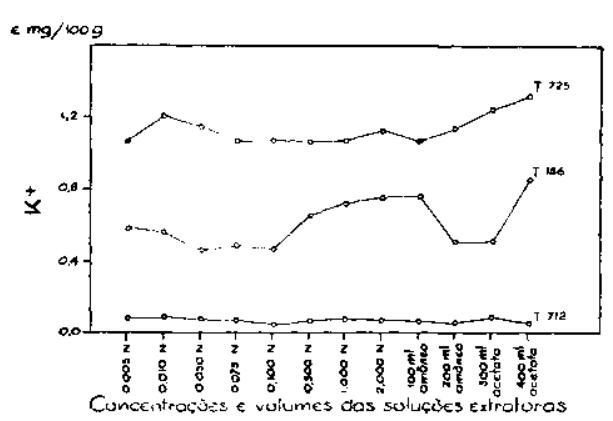

Figura 6. - Variação do teor de K+ na Terra-Roxa, segundo os diferentes extratores.

solos tiverem uma gênese como os do Estado de São Paulo.

b) Há vantagens na marcha analítica pelo emprêgo do $\mathrm{HNO}_{3}$ $0,05 \mathrm{~N}$, mas não é preciso que a normalidade do ácido seja exata, porque a permuta de bases é independente da concentração (dentro de certos limites). 
c) Nas condições de trabalho empregadas neste estudo, a extroção das bases trocáveis do solo é uma propriedade independente da concentração do extrator. É também independente do tipo de extrator (estudado para o acetato de amônio e ácido nítrico).

d) As bases retidas nos minerais primários e aquelas existentes nas formas "fixas" de Catani e Küpper (3), não são removidas pelo ácido nítrico até $2 \mathrm{~N}$.

e) Como a nutrição mineral das plantas em $\mathrm{K}, \mathrm{Ca}$ e $\mathrm{Mg}$ se processa por fenômenos de troca de bases, e não se admitindo que os vegetais criem condições mais enérgicas que o extrator $\mathrm{HNO}_{3} 2 \mathrm{~N}$ para remover as bases das formas "fixas" e "primárias", tal nutrição é feita sòmente pelos elementos que estão adsorvidos no complexo, isto é, trocáveis.

\section{SOIL BASES AND THEIR BEHAVIOR UNDER ACID EXTRACTION}

\section{SUMMARY}

Some soils of the state of São Paulo possess a certain amount of bases that cannot be considered as exchangeable. The behavior of exchangeable and non-exctiongeable boses in some soil types wos studied by means of cation extraction with nitric acid solutions of the following concentrations: $0.005 \mathrm{~N}, 0.01 \mathrm{~N}, 0.05 \mathrm{~N}, 0.075 \mathrm{~N}$, $0.5 \mathrm{~N}, 1 \mathrm{~N}$, and $2 \mathrm{~N}$. The exchangeable cations in the samples were determined by leaching the soil with normal ammonium acetate at $\mathrm{pH} \mathrm{7,} \mathrm{using} \mathrm{for} \mathrm{aliquots} \mathrm{of}$ the same samples $100,200,300$, and $400 \mathrm{ml}$ of the solution. Various soil types were used in these studies, including the latosols, red-yellow podzolic, and "terra-roxa", all with low content of bases. The results obtained permit the following conclusions:

a) all concentrations of nitric acid tried removed the same omount of boses as was removed by the ammonium acetate method; the content variation leached by the nitric acid was identical for any volume of ammonium acetate used;

b) it was confirmed that acid solutions may be employed for the determination of bases in semi-tropical soils as those of the state of São Paulo;

c) non-exchangeable bases were not affected by acid solutions as strong as $2 \mathrm{~N}$;

d) the exchangeoble property is characteristic and remains constant over a large range of acid solution concentrations;

e) since the uptake of bases by plants is considered an exchange phenomenon and it is hard to conceive that plant roots may create more energetic conditions than those resulting from $2 \mathrm{~N}$ nitric acid treatment, it is assumed that only exchangeable bases in these soils are available for plant absorption. The amount of individual exchangeable bases is thus critical for the study of soil fertility. 


\section{LITERATURA CITADA}

1. CATANi, R. A. Estudos do potássio nos solos do Estado de São Paulo. São Paulo, Companhia brasileiro de Potassa e Adubos, Indústria e Comércio. s. 1., Tipografia I. Ferracina, s.d. 39 p. (Separata com extratos de Tese de Concurso)

2. —_ \&ALLO, J. R. A extração do manganês e suas formas de ocorrêncio em alguns solos do Estado de São Paulo. Bragontia 11:[255]-266. 1951.

3. - \& KÜPPER, A. As formas "trocável" e "fixa" dos cations $\mathrm{K}+, \mathrm{Ca}++$ e $\mathrm{Mg}++$ nos solos do Estado de São Paulo. Bragantia 9:[185I-192.' 1949.

4. \& PAIVA, J. E. (neto). Dosagem do $\mathrm{K}$ e $\mathrm{Na}$ pelo "Fotômetro de chama". Sua oplícação na análise de solo. Bragantia 9:[175]-183. 1949.

5. KOLTHOFF, S. M. \& SANDELL, E. B. Textbook of quantitative inorganic analysis. New York, The Macmillan Co., 1943. p. 380-381.

6. KÜPPER, A. Dosagem do magnésio pela 8-hidroxiquinolina. In Reunião brasileira de Ciência do Solo, Rio de Janeiro, 1953. Anais. p. 144.

7. PAIVA, 3. E. (neto), CATANI, R. A., QUEIROZ, M. S. \& KUPPER, A. Contribuiçāo ao estudo dos métodos analíticos e de extraçăo para a caraterização química dos solos do Estado de São Paulo. In Reunião brasileira de Ciência de Solo, 1.a, Rio de Janeiro, 1947. Anais. Rio de Janeiro, Soc. bras. Sci. Solo, 1950. p. [79]-108.

8. PIPER, C. S. Soil and plant analysis. New York, Interscience Publishers, Inc., 1944. p. [154]-155.

9. SCHOLLENBERGER, C. J. \& SIMON, R. H. Determination of exchange capacity and exchangeable bases in soil ammonium acetate method. Soil Sci. 59:[13]-24. 1945.

10. VERDADE, F. C. Observações sôbre métodos de determinação da capacidade de troca de cations do solo. Bragantia I5:[393]-401. 1956. 